\title{
Failure analysis and optimum structure design of PDC cutter
}

\author{
Chunyan Kong*, Zheng Liang**, Derong Zhang*** \\ *College of Mechatronic Engineering, Southwest Petroleum University, 610500 Chengdu, China, \\ E-mail: kchy123456@139.com \\ **MOE Key Lab of Oil and Natural Gas Equipment, Southwest Petroleum University, 610500 Chengdu, China, \\ E-mail: liangz_2242@126.com \\ ***College of Mechatronic Engineering, Southwest Petroleum University, 610500 Chengdu, China, \\ E-mail: zdr3112@163.com
}

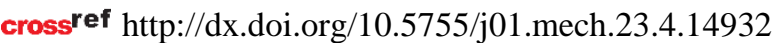

\section{Introduction}

PDC (Polycrystalline Diamond Compact) cutter is made of PCD (Polycrystalline Diamond) powder plus activator (Cobalt or Silicon) and WC (Wolfram Carbide) substrate and sintered under high temperature and pressure [1]. The PDC cutter is widely prevailed in the markets of measuring and cutting tools, down-hole tools of oil and gas drilling, mining and geothermal drilling industries. It owns key performance indicators including but not limited to wear resistance, high hardness, good thermal stability and impact toughness [2].

According to the results of statistic analyses and field surveys, the failure modes of PDC bit mainly involve the mechanical wear and fracture of cutters during normal drilling, accompanied with few occurrences of PCD stripping and cutter drop, wherein, the mechanical wear always occurs at the cutters on the top of crown, while fracture and stripping frequently occur in the cutters on the edge of crown [3]. As shown in Fig. 1, the fracture failure (41\%) of PDC cutter is in the highest proportion and it is more serious to adversely affect the drilling rate and rock cutting efficiency [4]. Therefore, the study on its failure modes is of high engineering significance to the comprehensive performance and service life of PDC bit.

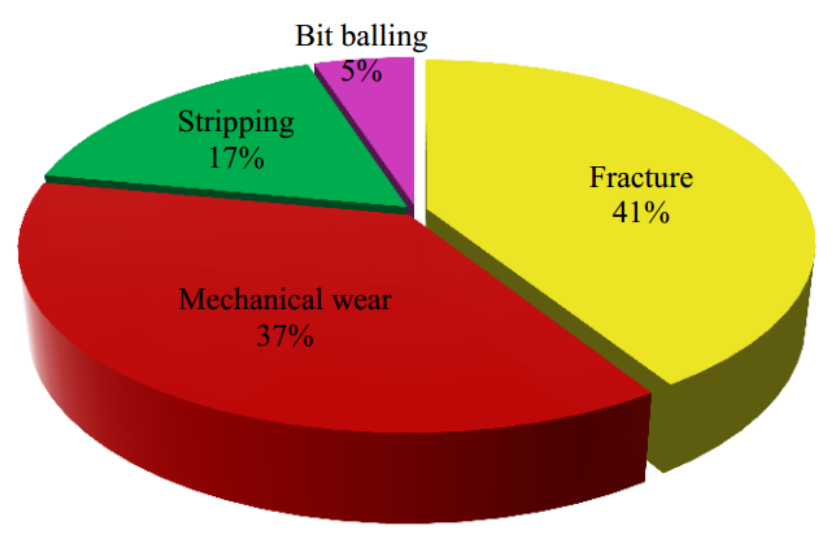

Fig. 1 Statistics on failures of PDC bit cutters

Li et al. [5] analyzed the failure types of PDC bits, and put forward the design, material manufacturing and the usage for the bits should be made to prevent PDC bits from earlier failures. Zhang [3,4] observed the macro and micro morphology of PDC bit cutter, and studied the failure causes. Appl et al. [6] developed a new cutter wear model from the cutting experiments. Wang et al. [7] established a new cutter-rock interaction model on the basis of experiments of cutting shale with PDC cutter. Kris [8] tested four different batches of PDC under monotonic and cyclic loadings, and researched fracture and fatigue of PDC. Pryhorovska et al. [9] built a finite element model of the process of PDC bit cutters cutting rocks, and simulated the rock linear and circular cutting processes for different shapes of PDC bit cutters. Li et al. [10] carried on the theoretical calculation and analysis of the cutting angle of PDC cutter. Wang et al. [11] analyzed the relationship of the cutting angle of PDC bit cutter and broken rock effect. David et al. [12] designed a kind of non-planar face PDC cutters, and won a good test effect. However, although the failure causes were presented in a qualitative analysis way for many years, little attention has been paid to the quantitative analysis.

\section{Failure analysis}

The failures of PDC cutters mainly include: (a) mechanical wear, (b) fracture and (c) stripping of PCD [8, 13], as shown in Fig. 2. The mechanical wear failure, approximately $37 \%$, is one of the most common failures to the cutters, and generally includes normal wear and abnormal wear. The normal wear is an inevitable drilling wastage, which is represented by microscopic and macroscopic abrasions without evident breakage or fracture. The abnormal wear is usually caused by improper operations or instantaneous impacts and represented by stripping and breakup of cutters.
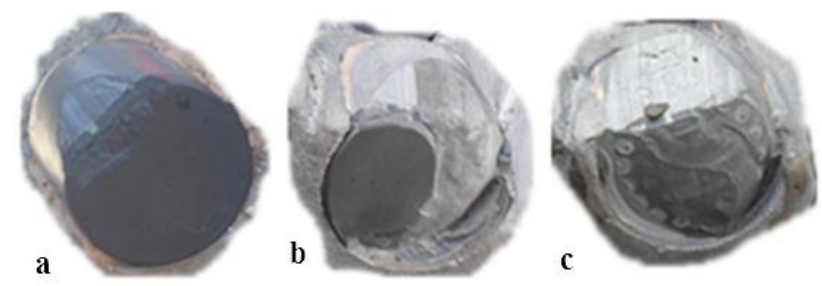

Fig. 2 Failure modes of PDC cutter: (a) mechanical wear, (b) fracture and (c) stripping

The abrasive particles will be forced by the contact stress into relative movement along the friction surface, while WC and PCD finishes will be misplaced in the hard particle movement direction, to cause the abrasive loss, as shown in Fig. 3 and Fig. 4. From the electronic microscope photographs of WC abrasion [14], it can be found that the 
friction trend and abrasive loss are in consistent with the cutting direction, there exist a certain quantity of voids and cavities, but there is no evident furrow or groove; only light microscopic scratches consistent with the cutting direction are found on PCD surface for that the rigidity of PCD is higher than the rigidity of abrasive particles, and the concentrated stress generated from the breakage of abrasive cannot cause damages to PCD.

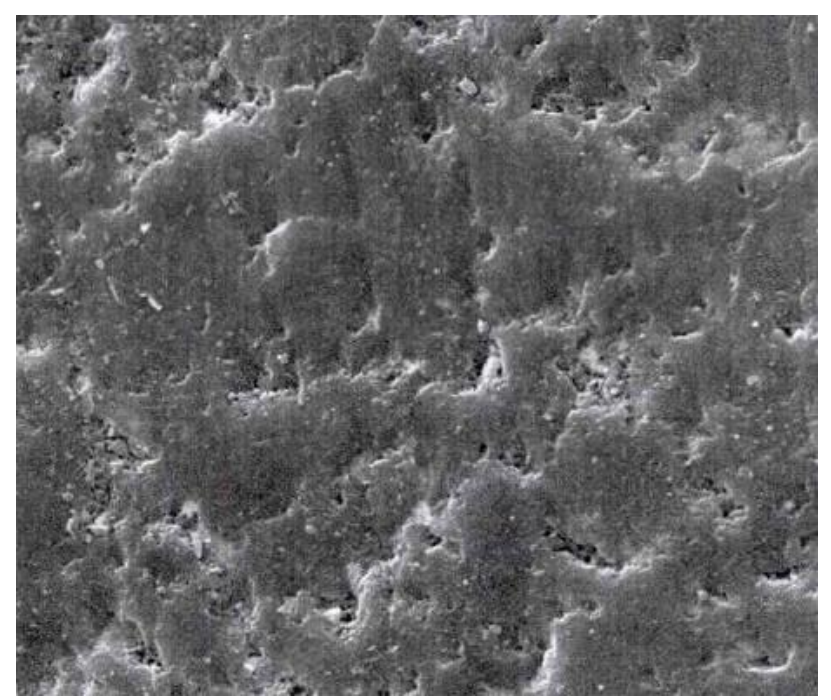

Fig. 3 Abrasion of PCD $(\times 5000$ times $)$

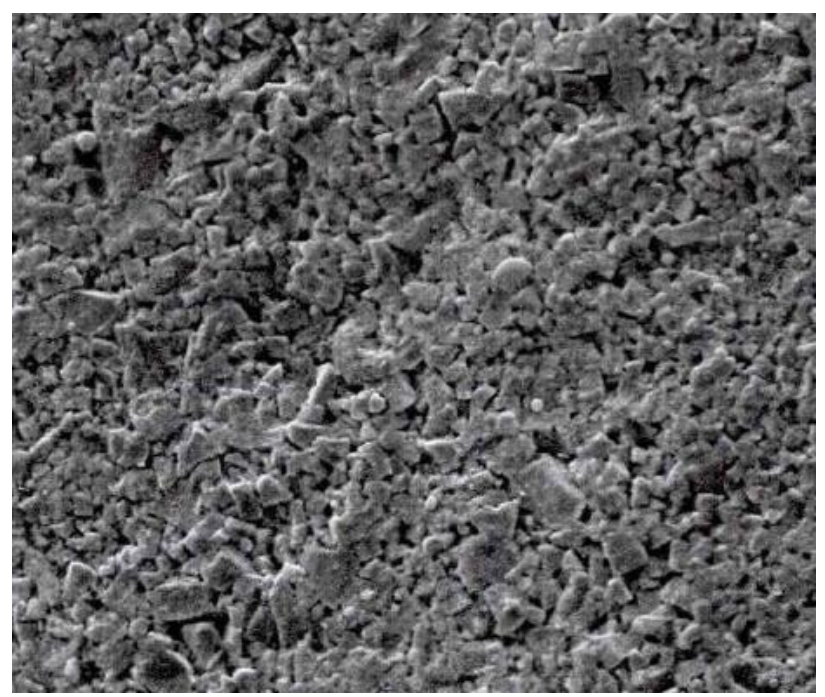

Fig. 4 Abrasion of WC $(\times 5000$ times $)$

Fracture failure of PDC includes the breakage of an entire cutter and fatigue fracture in a local part [15], which are mainly caused by: 1 . Low impact resistance, namely the insufficient crystalline boundary cohesion among WC, Co and PCD materials on PDC cutters, or the inherent holes, cavities, dislocation or other defects of the materials are easily subject to the impact to generate cracks or even breakage [16]. 2. The stick-slip vibration during drilling, which will cause great impact of instant overload to the PDC cutters. 3. The cyclic action during drilling, which will cause accumulation of stress fatigue, expansion and deepening of cracks, and result in the breakage of the PDC cutters.

The PCD stripping is mainly caused by: 1 . The residual stress, mechanical wear and temperature changes in the PDC cutters, which will cause the reduction of crys- talline cohesion to result in local cracks inside PCD, or even breakup or stripping in a large area. 2. Poor thermal stability of PCD, namely the stability of polycrystalline will be fully destroyed when the temperature of the PDC cutters exceeds $1200^{\circ} \mathrm{C}$ during cutting [17], to cause changes to the texture and impairment to performance [18]. 3. Great difference between the thermal expansions of PCD and WC, namely the thermal stress from the heating by friction will decrease the bonding strength between them, to cause, together with the external forces, the generation of micro-cracks and acceleration of PCD stripping.

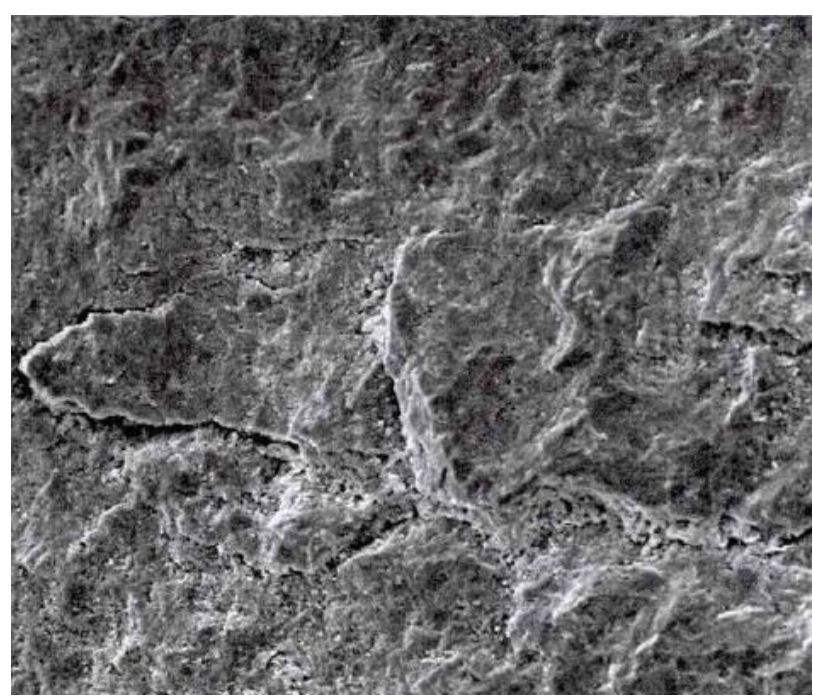

Fig. 5 PCD stripping caused by impact $(\times 1000$ times $)$

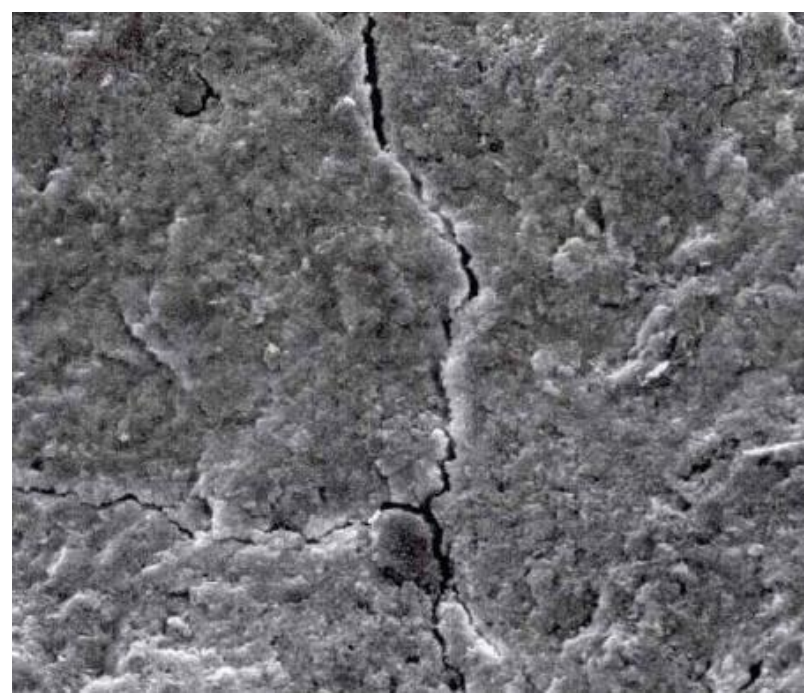

Fig. 6 WC stripping \& cracks $(\times 2000$ times $)$

Upon analysis on Fig. 5 and Fig. 6, when PDC cutters are impacted, the dislocation will be caused between the particles of bonding phase Co and carbide phase WC, and therefore the stress concentration will be caused due to the accumulation of dislocation and transposition [19]; simultaneously, the inconsistent plastic deformation of $\mathrm{Co}$ and WC under high stress will cause de-bonding which results in vacancies among the crystal particles; after certain cycles, the voids and micro-cracks will be formed and then communicated with each other to accelerate the development of their intra-crystalline expansion into the trans-crystalline breakage. Such micro-cracks, generally originated from the stripping surface of PCD, 
will be expanded and deepened to cause new micro laminar stripping.

\section{Analysis of finite element}

\subsection{Establish the mechanical model}

The PDC bit breaks rock by means of scrape and shear. The PCD is the original cutting part which contacts direct with the rock (Fig. 7). The PDC cutter stress mainly within $180^{\circ}$ arc of PCD layer, and it is the cutting angle $\theta$, eat into strata depth $\Delta h$, WOB (Weight on Bit) and lithology of a relationship. The cutter suffered by the load can be decomposed into three space vectors: the vertical loads opposites WOB direction is $\mathrm{Pa}$, the tangential load that opposite to the cutter movement direction of the cutter is $P_{t}$, and the lateral load is $P_{h}$. The sum of all the load projection is balanced with WOB [18].

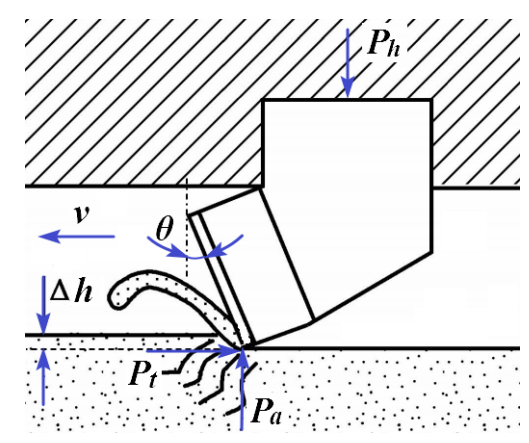

Fig.7 PDC cutting

According to the statistic in the field application, PDC bit in $8 \frac{1}{2}$ inch hole is the most consumed type in oil field. This cutter's profile is cylinder and out diameter is $16 \mathrm{~mm}$. By using ANSYS Workbench to establish a me- chanical model of PDC cutter (Fig. 8), based on the actual condition of PDC cutter, to conduct the structural dynamics analysis on the PDC cutter. To simplify the analysis model, the factors such as temperature, speed and the impact of lateral load are not taken into consideration.

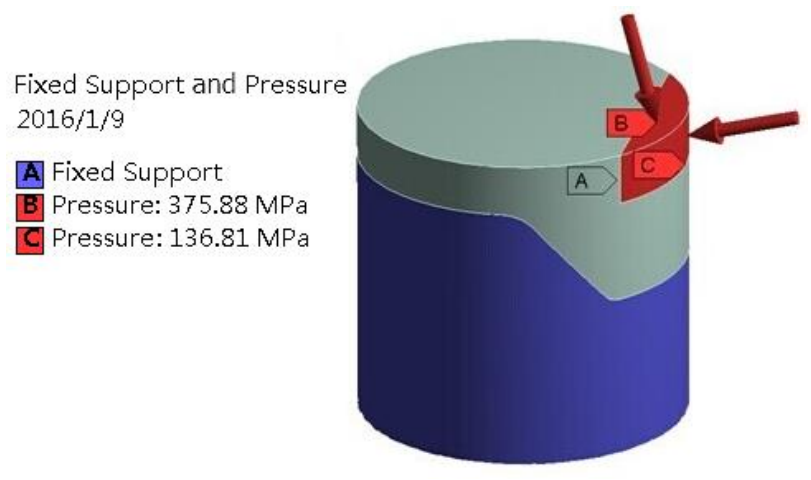

Fig. 8 Boundary conditions

\subsection{Material properties}

The cutting element of PDC cutter is PCD layer, the lower part is WC substrate. The property of two materials defined as shown in Table 1 [9].

\subsection{Boundary conditions}

1. The boundary conditions: The cemented carbide substrate of PDC cutter is embedded in the perforations on the drill bit body. Therefore, that part is set to a fixed constraint, as shown in Fig. 8.

Material properties

\begin{tabular}{|c|c|c|c|c|c|}
\hline Material & $\begin{array}{c}\text { Density } \\
\mathrm{kg} / \mathrm{m}^{3}\end{array}$ & $\begin{array}{c}\text { Elasticity } \\
\mathrm{MPa}\end{array}$ & Poisson's ratio & $\begin{array}{c}\text { Tensile strength } \\
\mathrm{MPa}\end{array}$ & $\begin{array}{c}\text { Compressive strength } \\
\mathrm{MPa}\end{array}$ \\
\hline $\mathrm{WC}$ & 15000 & 640000 & 0.22 & 1120 & 5460 \\
\hline $\mathrm{PCD}$ & 4100 & 800000 & 0.08 & 1300 & 7400 \\
\hline
\end{tabular}

2. Load: Assumed the cut-in depth of PDC cutter into the rock is $2 \mathrm{~mm}$, the load $P$ is $400 \mathrm{MPa}, \theta$ is $20^{\circ}$, then establish Cartesian coordinates and cylindrical coordinates of PDC cutter. As long as the maximum stress of the cutter under load is no more than the tensile strength, the failure will not happen. The broken situation of cutter under load can be analyzed through the internal stress and distribution at $400 \mathrm{MPa}$. The loading matrix as follows:

$$
\begin{aligned}
& {\left[\begin{array}{lll}
P_{t} & P_{a} & P_{h}
\end{array}\right]=P\left[\begin{array}{ccc}
-\cos \theta & 0 & 0 \\
0 & \sin \theta & 0 \\
0 & 0 & 0
\end{array}\right],} \\
& {\left[\begin{array}{lll}
P_{x} & P_{y} & P_{z}
\end{array}\right]=\left[\begin{array}{ccc}
-\sin \theta & 0 & 0 \\
0 & \cos \theta & 0 \\
-\cos \theta & 0 & 0
\end{array}\right]\left[\begin{array}{l}
P_{t} \\
P_{a} \\
P_{h}
\end{array}\right],}
\end{aligned}
$$

\subsection{Strength analyze}

The mesh of three-dimensional finite element was automatically divided by the software. This will make the PCD layer grid more intensive. The unit uses 8-node 6-Icosahedron, SOLID187 of solid elements, units totaled up to 285641 . The whole number of nodes is 420312 . Linear static equation is $[K]\{x\}=[F]$. The direct solver is the inverse matrix $[K]^{-1}$ obtained by decomposing the coefficient matrix $[K]$, and got the result of $\{x\}=[K]^{-1}[F]\{x\}$.

By means of von-Mises criteria, the figures of material failure stress, the maximum shear stress and maximum principal stress are shown in Fig. 9.

According to PDC cutter's equivalent stress and the principal vector stress, we can arrive at the conclusion that among these vector stresses the maximum stress area is tensile stress. Because compressive strength of PCD 
material is about 6 times over that of tensile strength, so the mainly failure of PDC cutter was caused by tensile stress through the distribution of stress isoline; simultaneously, the maximum equivalent stress of PDC cutter appeared near the joint surface of the composite layer and gradually extends outward. Therefore, the destruction of the cutter is mainly beginning from the combination of surface area, PCD loses its back-up, and the destruction then gradually extended to the surface.

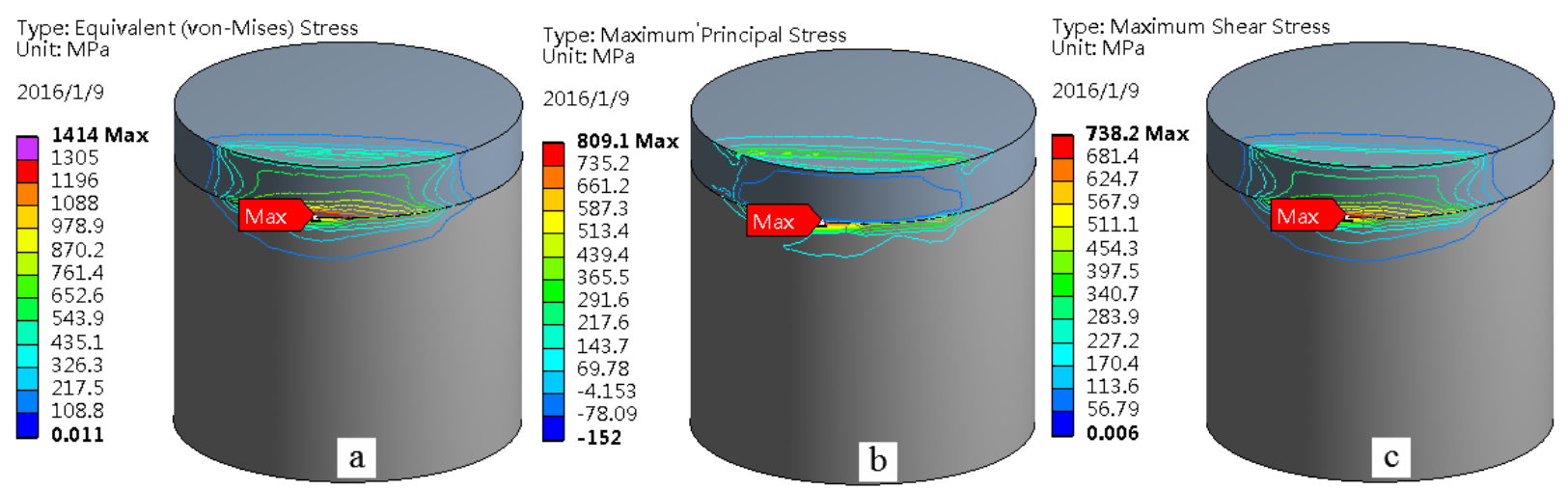

Fig. 9 Conventional PDC cutter's stress isoline: (a) equivalent stress, (b) maximum principal stress, (c) maximum shear stress

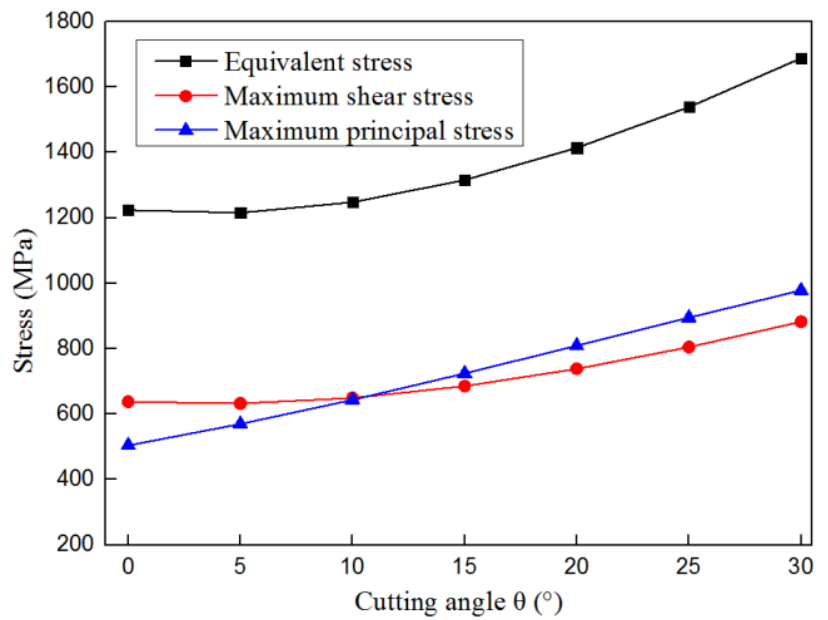

Fig.10 Conventional PDC cutter's stress and cutting angle

PDC cutter stresses vary with the change of the cutting angle $\theta$ curve as shown in Fig. 10, the analysis results show that: The stresses of PDC cutter increases along with the cutting angle at $\theta>5^{\circ}$; PDC tooth equivalent stress is greater than the tensile strength and failure occurred. The stress curve fitting in Fig. 10, get the computational formula of equivalent stress $\sigma_{s}$, maximum principal stress $\sigma_{p}$ and maximum shear stress $\sigma_{\tau}$ :

$$
\begin{aligned}
& \sigma_{s}=0.684 \theta^{2}-5 \theta+1225, \\
& \sigma_{p}=0.1 \theta^{2}+13 \theta+500, \\
& \sigma_{\tau}=0.373 \theta^{2}-3 \theta+640 .
\end{aligned}
$$

The calculation results of formula (3)-(5) compared with the finite element analysis results, among them, the maximum error of $\sigma_{s}$ is $1.09 \%$, the maximum error of $\sigma_{p}$ is $1.12 \%$ and the maximum error of $\sigma_{\tau}$ is $1.22 \%$. Therefore, formula (3)-(5) can be used to calculate different cutting angle of PDC cutter stress, to determine the PDC cutter failure, can also be used to guide the design and installation of PDC cutter.

The cutting angle of the PDC cutter determines the cutting force, that is, the size of the cutting force is proportional to the cutting angle. Therefore, the said angle is set as objective function to design of the PDC cutter structure.

\section{Structure design and analysis of multi-face PDC reinforced cutter}

For the failure of conventional cylindrical PDC cutter, the usual solution is to groove on the surface of WC or change process, shape and structure of the proportion of PCD, so as to improve the performance of composite sheet itself, but on the combined surface of internal stress and shear stress distribution and the improvement of the size are very limited [12]. Therefore, this article in-depth analysis of the failure mechanism, proposed the multi-face (i.e., Non-planar) PDC strengthen cutter in the view of the structure and relative process skill, will extend the service life of PDC bit, and have important practical application value and engineering significance.

\subsection{Structure design of multi-face PDC reinforced cutter}

The structure of multi-face PDC reinforced cutter is shown in Fig. 11, it includes the PCD body and WC substrate. Multi-face meshing structure means: the mating surface of the PCD body and the WC substrate are constituted by four different locations where each other are not on the same spatial space surface, which is $A-B-C-D$ multiface surface.

As shown in Fig. 11, thickness from plane $A$ to the surface of PCD cutter is $t$; plane $A$ and $D$ are parallel to the both sides(upper and lower) of the cylindrical cutter, its vertical distance is $H$; plane $B$ and $C$ formed to each other a " $V$ " shape angle $\varphi$ with oblique plane; plane $A, B$ and $C$ of the intersection with the plane $B, C$ and $D$ of the intersection in the horizontal plane of projection distance is $L$; plane $B$ and $C$ symmetrical to each other. Meanwhile, on the PCD plane $(A-B-C-D)$, a closed surface is designated where the twenty hemisphere with diameter $\phi$ corresponding to the ball pit of the WC substrate and weaved to each other. 


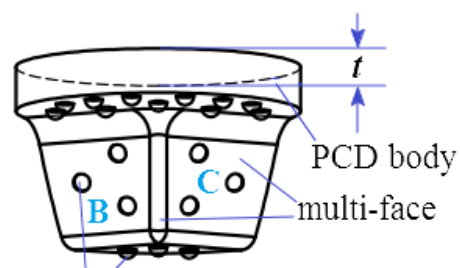

ball convex body
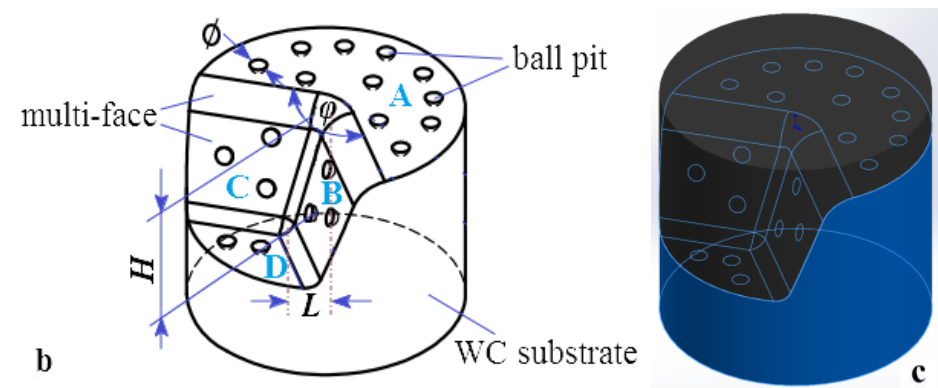

Fig. 11 Multi-face PDC reinforced-cutter's structure: (a) PCD body, (b) WC substrate, (c) solid model

The structure size of multi-face PDC reinforced cutter related to lithology, eating into the stratum depth and the cutting angle on the bit, it has to be designed based on actual working conditions. This structure mentioned in this paper is designed to change the impact of the external load on the cutter where its internal stress field distribution and size, strengthen anti-destruction capability of the cutter and further improve their cutting performance.

As $16 \mathrm{~mm}$ cutter example, the structural parameters: $\theta=20^{\circ}, \varphi=130^{\circ}, H=5 \mathrm{~mm}, L=2.84 \mathrm{~mm}, t=2.5 \mathrm{~mm}$, $\Delta h=2 \mathrm{~mm}$. The distance between the $\varphi$ arc centerline of the multi-face meshing surface and the PDC axis is $2 \mathrm{~mm}$.

\subsection{Results of analysis}

The finite element analysis on multi-face PDC reinforced cutter by using the same as the load and boundary conditions of conventional PDC cutter, the results as shown in Fig. 12. The maximum equivalent stress and the maximum principal stress of PDC reinforced cutter appears on the plane $D$, and the principal stress area from the cutter edge contact area gradually extend outward (Fig. 12, a, c); the maximum shear stress appears on the surface PCD. Under this situation, the cutter is mainly destroyed by fatigue wear.
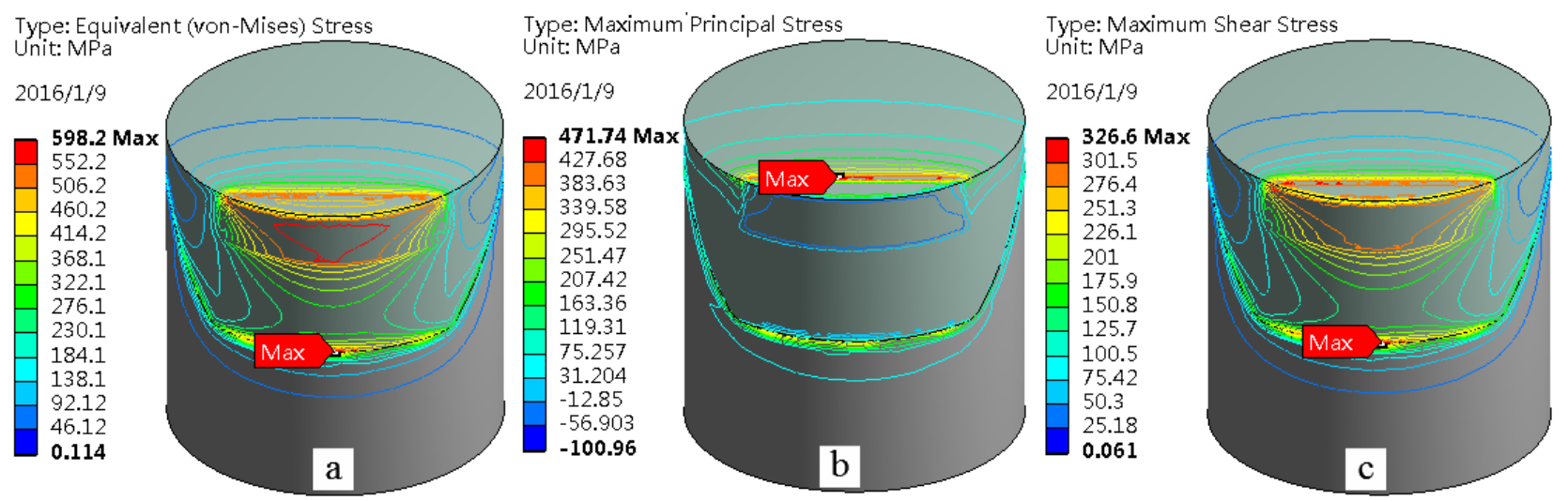

Fig. 12 PDC reinforced-cutter's stress isoline: (a) equivalent stress, (b) maximum principal stress, (c) maximum shear stress

Table 2

Stresses comparison between two kinds of PDC cutters

\begin{tabular}{|c|c|c|c|}
\hline Type & $\begin{array}{c}\text { Equivalent stress } \\
\mathrm{MPa}\end{array}$ & $\begin{array}{c}\text { Max principal stress } \\
\mathrm{MPa}\end{array}$ & $\begin{array}{c}\text { Max shear stress } \\
\mathrm{MPa}\end{array}$ \\
\hline Conventional PDC & 1414 & 809.1 & 738.2 \\
\hline Multi-face PDC & 598.2 & 471.7 & 326.6 \\
\hline
\end{tabular}

Stresses of the two kinds of cutters contrast are shown in Table 2. The equivalent stress, maximum shear stress and maximum principle stress of multi-face PDC reinforced cutter are far less than conventional one. The equivalent stress of multi-face PDC reinforced cutter fell $57.5 \%$, the maximum principal stress decreased $41.7 \%$ and the maximum shear stress decreased $55.8 \%$. It proved that multi-face structure can reduce the force acting and the internal stress distribution and size of the PDC reinforced cutter. Meanwhile, the integration of multi-face and meshing of the hemisphere with the ball pit did enhance the binding of the two materials which highly prevents the detachment of PDC layer from the WC substrate, thus extending their service life.

By using the cutting angle $\theta$ as parameters, the improved multi-face PDC reinforced cutter stresses were calculated and the result as shown in Fig. 13. The maximum principal stress significantly increased with the increase of the cutting angle at $\theta>5^{\circ}$. Maximum shear stress change with the change of the cutting angle was small. Cutter's equivalent stress changes little at $0<\theta \leqslant 25^{\circ}$; equivalent stress will increase obviously at $\theta>25^{\circ}$. Therefore, the cutting angle of multi-face PDC reinforced cutter is suggested between $5^{\circ}$ and $25^{\circ}$. 
Based on Fig. 10 and Fig. 13, it is clearly that: Compared with conventional PDC cutter, multi-face PDC reinforced cutter equivalent stress, maximum shear stress and maximum principal stress have been improved. The structure parameters of PDC reinforced-cutter maintained the following relationship: $f(\varphi, \phi, H, L, \Delta h)=\theta$. Based on the above relationship, the size of cutter structure can be well adjusted to fit into actual working condition and achieved optimum cutting effect.

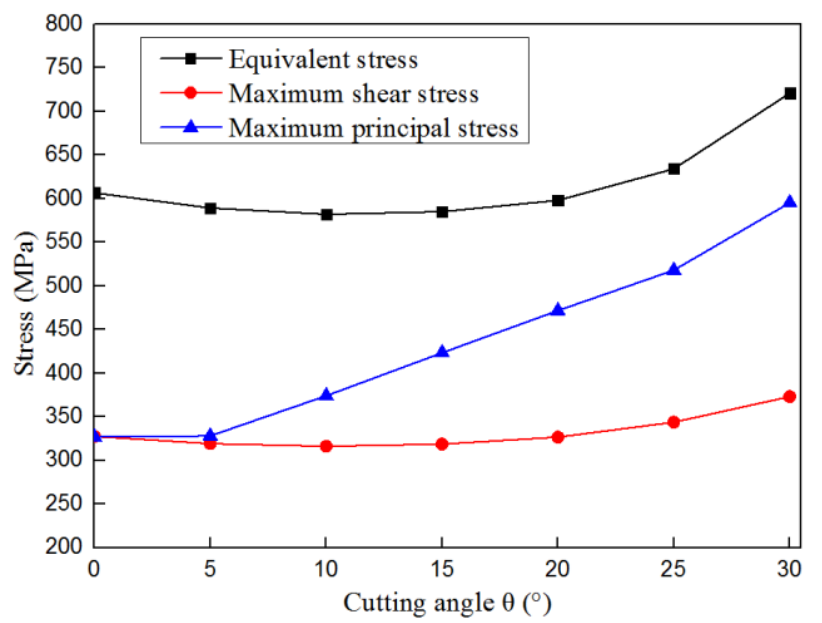

Fig. 13 Multi-face PDC reinforced-cutter's stress and cutting angle

\section{Conclusions}

1. An analysis of PDC cutter failure shows that the failure modes include mechanical wear, fracture and stripping. The maximum equivalent stress of conventional PDC cutter appeared near the joint surface of the composite layer and gradually extends outward. Therefore, the fracture and stripping of cutter is mainly beginning from the combination of surface area, PCD loses its back-up and the destruction then gradually extended to the surface.

2 . The structure parameters of PDC reinforcedcutter maintained the following relationship: $f(\varphi, \phi, H, L$, $\Delta h)=\theta$. Based on the above relationship, the size of cutter structure can be well adjusted to fit into actual working condition and achieved optimum cutting performance. The cutting angle of multi-face PDC reinforced cutter is suggested between $5^{\circ}$ and $25^{\circ}$.

3. The results of the finite element analysis show that "Non-planar mesh structure" of the multi-face PDC reinforced cutter will change external variable load of the cutting edge into internal surface load of multi-face, and it changed the nature of the stress of the teeth, make the cutter has high resistance to shear failure capacity. The equivalent stress and maximum shear stress of the improved multi-face PDC reinforced cutter are far less than conventional one. It proved that multi-face structure can reduce the force acting and the internal stress distribution and size of the PDC reinforced cutter. Meanwhile, the integration of multi-face and meshing of the hemisphere with the ball pit did enhance the bonding force between PCD and WC, which highly prevents the detachment of PCD layer from the WC substrate, it can effectively reduce the fracture and stripping the probability of occurrence of the failure, thus extending their service life.

\section{Acknowledgement}

The financial support received from the State Ministry funded project: Researching and Producing of vertical subsea tree, Southwest Petroleum University Graduate Innovation Fund (Grant No. CX2014BY06) are gratefully acknowledged.

\section{References}

1. De S, Heaney PJ, Fei Y, et al. 2004. Micro-structural study of synthetic sintered diamond and comparison with carbonado, a natural polycrystalline diamond, American Mineralogist 89, 438-446. http://dx.doi.org/10.2138/am-2004-2-325.

2. Fang Z, Griffo A, White B. 2001. Chipping resistant polycrystalline diamond and carbide composite materials for roller cone bits, SPE Annual Technical Conference and Exhibition in New Orleans, SPE paper number 71394 .

http://dx.doi.org/10.2118/71394-MS.

3. Zhang FX, Huang ZQ, Zhou Y. 2015. Failure analysis of PDC bit cutter, Oil Field Equipment 44, 44-49 (In Chinese).

http://dx.doi.org/10.3969/j.issn.1001-3482.2015.09.11.

4. Zhang FX. 2013. PDC bit cutter failure analysis and impact abrasion resistance performance test research. Chengdu: Southwest Petroleum University, (In Chinese).

5. Li GA, Song QS. 2002. The analysis of failure of PDC well bits, J. Huazhong Univ. of Sci. \& Tech. (Nature Science Edition) 30, 62-64 (In Chinese). http://dx.doi.org/10.3321/j.issn:16714512.2002.01.022.

6. Appl FC, Wilson CC, Lakshman I. 1993. Measurement of forces, temperatures and wear of PDC cutters in rock cutting, Wear 169, 9-24.

http://dx.doi.org/10.1016/0043-1648(93)90386-Z.

7. Wang JJ, Zou DY, He RQ. 2014. Experimental study on force of PDC cutter breaking rock, Procedia Engineering 73, 258-263.

http://dx.doi.org/10.1016/j.proeng.2014.06.196.

8. Zacny K, Robotics H. 2012. Fracture and fatigue of polycrystalline-diamond compacts. SPE Drilling \& Completion 27, 145-157. http://dx.doi.org/10.2118/150001-PA.

9. Pryhorovska TO, Chaplinskiy SS, Kudriavtsev IO. 2015. Finite element modelling of rock mass cutting by cutters for PDC drill bits. Petroleum Exploration and Development 42, 888-892. http://dx.doi.org/10.1016/S1876-3804(15)30087-2.

10. Li SS, Ma DK, Hou JK. 1996. Precise calculation and analysis of working angles of PDC cutters, JSWPI 18, 67-72 (In Chinese). http://dx.doi.org/10.3863/j.issn.10002634.1996.04.013.

11. Wang ZQ, Zhou YH. 2009. Study on rock breaking regulation in optimizing cutting angle of PDC bit. Coal Mine Machinery 30, 49-51 (In Chinese). http://dx.doi.org/10.3969/j.issn.10030794.2009.08.022.

12. David S, Anthony D, Danielle F, et al. 2014. Innovative non-planar face PDC cutters demonstrate $21 \%$ 
drilling efficiency improvement in interbedded shales and sand, IADC/SPE Drilling Conference and Exhibition held in Fort Worth, SPE paper number 168000. http://dx.doi.org/10.2118/168000-MS.

13. Zeuch DH, Finger JT. 1985. Rock breakage mechanisms with a PDC cutter, The 60th SPE Annual Technical Conference and Exhibition in Las Vegas, NV, SPE paper number 14219 . http://dx.doi.org/10.2118/14219-MS.

14. Fan YT, Huang ZQ, Gao DL, Li Q. 2011. Experimental study of an $\mathrm{Al}_{2} \mathrm{O}_{3} / \mathrm{WC}-\mathrm{Co}$ nanocomposite based on a failure analysis of hammer bit, Eng Fail Anal 18, 1351-1358. http://dx.doi.org/10.1016/j.engfailanal.2011.03.028.

15. Valentine K, Aaron D, Neal M. 2014. Impact fatigue fracture of polycrystalline diamond compact cutters and the effect of microstructure. International Journal of Refractory Metals and Hard Materials 46, 145-151. http://dx.doi.org/10.1016/j.ijrmhm.2014.06.003.

16. Zhuang DH. 2009. Failure analysis, Shanghai: East China University of Science and Technology Press, 3248.

17. Sneddon MV, Hall DR. 1988. Polycrystalline diamond: manufacture, wear mechanisms and implications for bit design. Journal of Petroleum Technology 12, 1593-1601. http://dx.doi.org/10.2118/17006-PA.

18. Gamal M G, Michele M, Mohamed A. 2011. A mathematical model to compute the PDC cutter wear value to terminate PDC bit run, SPE Middle East Oil and Gas Show and Conference in Manama, SPE paper number 140151. http://dx.doi.org/10.2118/140151-MS.

19. Zhou Y, Huang ZQ, Zhang FX, et al. 2014. Experimental study of WC-Co cemented carbide air impact rotary drill teeth based on failure analysis. Eng Fail Anal 36, 186-198. http://dx.doi.org/10.1016/j.engfailanal.2013.10.008.
Chunyan Kong, Zheng Liang, Derong Zhang

\section{FAILURE ANALYSIS AND STRUCTURE OPTIMUM DESIGN OF PDC CUTTER}

\section{S u m m a r y}

The PDC (Polycrystalline Diamond Compact) cutter is widely prevailed in the markets of measuring and cutting tools, down-hole tools of oil and gas drilling, mining and geothermal drilling industries. However, PDC cutters failure results in reduced bit life and low efficiency rock breaking thereby limiting the popularity and application of drilling technology. Drilling practice shows that the failures of PDC cutters mainly include mechanical wear, fracture and stripping of PCD (Polycrystalline Diamond). Finite element models of conventional PDC cutter and the multi-face PDC reinforced cutter were established, and the failure reasons were discussed by simulation. It was found that the residual stress and mechanical wear in the PDC cutters, which will cause the reduction of crystalline cohesion to result in local cracks inside PCD; the maximum equivalent stress of conventional PDC cutter appeared near the joint surface of the composite layer and gradually extends outward. Therefore, the fracture and stripping of cutter is mainly beginning from the combination of surface area, PCD loses its back-up and the destruction then gradually extended to the surface. The size of the cutting force is proportional to the cutting angle of conventional PDC cutter, so it can set as objective function to design of the PDC cutter structure. Designed the multi-face PDC reinforced cutter will change external variable load of the cutting edge into internal surface load of multi-face, and it changed the nature of the stress of the teeth, make the cutter has high resistance to shear failure capacity. By finite element simulation of conventional PDC cutter and multiface PDC reinforced cutter stresses, the results show that the multi-face PDC reinforced cutter significantly reduces the internal stress distribution and the peak load, enhance the bonding force between PCD and WC, which can effectively reduce the fracture and stripping the probability of occurrence of the failure, and have great engineering significance to the comprehensive performance and service life of PDC bit.

Keywords: failure analysis, multi-face PDC reinforcedcutter, structure design, finite element simulation.

Received June 16, 2016

Accepted August 04, 2017 